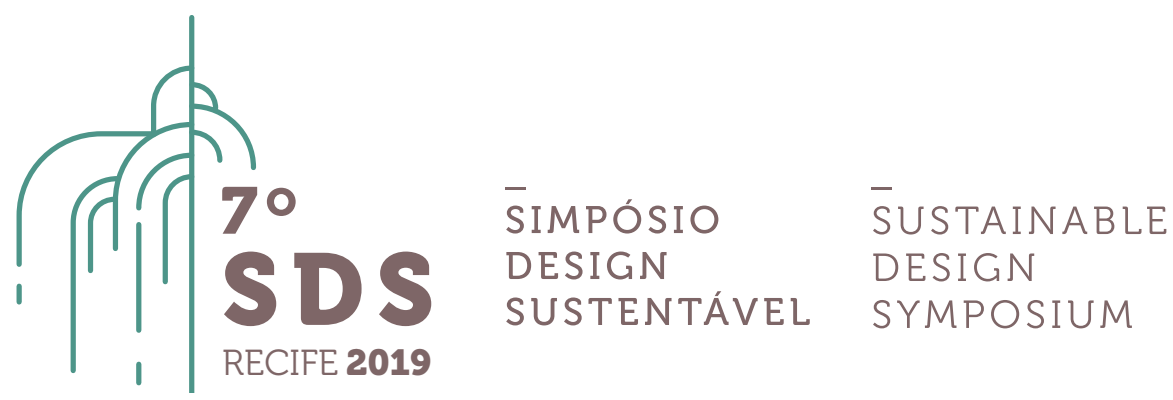

\title{
O Potencial do Design combinado ao Setor do Turismo como alternativa para a valorização dos recursos locais
}

\author{
$<$ Raquel Pereira Canaan $>^{1},<$ Alfredo Jefferson de Oliveira $>^{2}$ \\ ${ }^{1}$ Universidade do Estado de Minas Gerais, Raquel.pcanaan@gmail.com \\ ${ }^{2}$ Pontifícia Universidade Católica do Rio de Janeiro, afferson@puc-br
}

\begin{abstract}
Este artigo é resultado de uma pesquisa de doutorado que teve como objetivo compreender as possibilidades de ação do design junto ao setor de turismo para o desenvolvimento sustentável dos territórios, através da valorização de seus aspectos sociais, culturais, econômicos e ambientais. Ao longo desta pesquisa, foi possível identificar que os temas Turismo como vetor de desenvolvimento local e Design aplicado à valorização do território estão sendo cada vez mais abordados nacional e mundialmente, mas ainda há poucas discussões sobre os temas associados, que apresentam grande potencial. Entendese que o planejamento estratégico dos territórios pode apoiar bastante o setor, possibilitando o desenvolvimento de atividades complementares que beneficiem a comunidade local tanto no aspecto material quanto imaterial e, para tanto, algumas das sugestões são apresentadas no texto a seguir.
\end{abstract}

Keywords. Tourism, Sustainable Development, territory valorization, service design, experience, strategy

\section{Introdução}

Para iniciar o percurso desta pesquisa, parte-se do entendimento da evolução da atividade do design como prática projetual, desde a época da Revolução Industrial até os rumos que a mesma tomou nos tempos atuais, diante de uma mudança de cenário em todo o mundo, por estar essencialmente ligada à sociedade e suas modificações ao longo do tempo. Essa mudança trouxe à tona valores como a preservação do meio ambiente, a valorização dos recursos materiais e humanos locais, bem como a ativação do potencial das pequenas comunidades para gerar capacitação e, consequentemente, auto estima e renda, ampliando também seu campo de atuação, relacionado ao bem-estar das pessoas.

A proposta deste artigo é fruto de uma pesquisa de Doutorado que teve início ainda na graduação, na linha de investigação do Design aplicado à valorização de territórios, de forma a ativar seus aspectos econômicos, sociais, ambientais e culturais, o que encaminhou a uma perspectiva de trabalho junto a comunidades, pequenos grupos e arranjos, buscando melhorias e ativações locais.

O direcionamento da sociedade para uma maior conscientização tem despertado a atenção 
do individuo às próprias raízes e o local onde vive, englobando ambiente, cultura, sociedade e economia. É possível perceber uma tendência mundial que vem crescendo a cada dia, tomando espaço junto a setores diversos da sociedade. Na economia, no turismo, na comunicação, os interesses das comunidades têm se direcionado para o centro da questão, enfatizando o entendimento dos comportamentos e necessidades sociais, e não apenas os individuais.

\footnotetext{
“Muitas transformações estão acontecendo na sociedade e, consequentemente, fomentando tendências de participação, protagonismo do cidadão e organizações. Neste momento, nota-se a alteração nos padrões, em que os indivíduos, associações e empresas sociais se reúnem com o propósito de desenvolver melhorias. (Ganske, 2016)"
}

Quando se fala em identidade cultural, há uma relação direta com a imagem que determinado local apresenta de si mesmo e isso se relaciona ao setor produtivo abordado neste trabalho, o turismo, que tem demonstrado, cada vez mais, seu potencial e relevância mundiais na economia, trazendo à tona um papel no sentido de valorizar o que existe de mais significativo localmente. Isto é possível dentro do cenário que se delineia porque as pessoas passaram a viajar mais e a buscar experiências de imersão na cultura visitada, fatores que demonstram o grande potencial do turismo ligado à valorização do território e de sua identidade cultural.

\footnotetext{
“Atribuir um uso turístico a um território implica utilizar um espaço, público ou privado de lazer, para uma atividade econômica que o transforma em mercadoria e pode, portanto, ser comercializada. É nessa perspectiva que o turismo se coloca como um setor produtivo." (DIAS, 2006, p.189)
}

Do ponto de vista deste trabalho, a forma de atuação do design incluindo produtos, serviços e informações acentua a necessidade de repensar a prática de projeto e o papel do designer de facilitar e apoiar o desenvolvimento de inovações em uma comunidade, um território, uma cidade. Por esse motivo, entende-se que a atividade pode exercer impacto positivo na economia local e no turista; e o desenvolvimento gerado a partir dos negócios com hospedagem, alimentação, passeios, artesanato, dentre outros, pode resultar em um conjunto de práticas a serem exercidas de forma responsável.

Ao longo da pesquisa que gerou este artigo, foram encontradas muitas referências sobre Design e Turismo em separado, ou sobre sua atuação específica em áreas como comunicação e hotelaria, mas não no planejamento da atividade turística. Também foi possível perceber que os temas Turismo como vetor de desenvolvimento local e Design aplicado à valorização do território vem sendo cada vez mais abordados, ainda com poucas discussões destas duas temáticas reunidas, que apresentam grande potencial. A pesquisa então buscou compreender as possibilidades de atuação do design aplicado ao setor do turismo para o desenvolvimento sustentável de territórios, por meio da valorização de seus aspectos sociais, culturais, econômicos e ambientais. Como resultado, apresenta alguns encaminhamentos na área, que podem ser trabalhados de forma conjunta.

\section{O Potencial do Turismo Junto ao Desenvolvimento Local}

A partir da segunda metade do século XX, de acordo com o Ministério do Turismo, depois da Segunda Guerra Mundial e do desenvolvimento dos meios de comunicação em massa, o turismo passou a ocupar lugar de destaque no mundo, como uma das atividades econômicas mais 
expressivas. No cenário brasileiro, sua importância também cresce a passos rápidos. Segundo classificação oficial brasileira, trata-se de uma atividade do setor terciário, mais precisamente do setor de serviços, envolvendo hotelaria, gastronomia, entretenimento, dentre outros.

O turismo se apresenta como atividade de grande potencial, sendo um dos setores da economia que mais cresce, capaz de movimentar ainda outros setores, com grande competência no sentido de promover desenvolvimento local, potencial que tem despertado o interesse dos planejadores territoriais. Para Coriolano (2009), poucos subsetores da economia desfrutam da versatilidade e flexibilidade do turismo de se adaptar às condições próprias de cada território e de cada população. A autora coloca o setor como oportunidade estratégica para o desenvolvimento local e menciona que esta discussão tem sido cada vez mais frequente.

Cruz (2010) coloca que sua relevância tanto em economias desenvolvidas como em desenvolvimento se deve ao impacto que tem em nível local, regional e nacional em questão de geração de empregos e oferta de serviços. Isto porque pode estimular o consumo de bens e serviços locais, reabilitação da infraestrutura, além do incentivo à conservação do patrimônio histórico e valorização de hábitos, tradições e costumes. A presença de visitantes traz possibilidades de dinamizar os territórios, gerar riqueza e emprego e potencializar o desenvolvimento de ramos de atividade que satisfazem diretamente às necessidades dos visitantes e também dos moradores.

Por outro lado, um grande problema para a sustentabilidade dos destinos turísticos está relacionado ao aumento do fluxo de turistas, e o crescimento desordenado e sem planejamento, que acaba por prejudicar a comunidade local. De acordo com Garrido (2011), acredita-se que o desenvolvimento da atividade em bases planejadas, contando com os devidos mecanismos de controle e monitoramento, pode alcançar a redução de seus impactos negativos (p.37). Entende-se também que pode se configurar como uma oportunidade para reforçar os valores próprios de um lugar, reafirmar a cultura local, mesmo abrindo a sociedade às influencias do exterior.

Além de se destacar como fonte geradora de empregos diretos e indiretos, o turismo tem feito um caminho de interagir significativamente com a sociedade, a cultura e o meio ambiente das regiões hospitaleiras e em virtude da concorrência cada vez mais acirrada, tem considerado o planejamento estratégico como um papel relevante junto ao território. Especificamente no Brasil, são muitas as possibilidades de explorar de maneira mais efetiva seus aspectos peculiares, aliados ao setor do turismo, gerando retorno não somente econômico, mas de qualidade de vida e valorização da produção local.

Pensando no território brasileiro, entende-se que as riquezas materiais e imateriais são muitas, e podem ser exploradas e divulgadas de maneiras diversas, que não somente em artefatos físicos. A experiência emocional a ser vivenciada em uma viagem pode englobar rituais, atividades diárias, laços de amizade e cooperação que ficarão guardados não somente nas casas dos visitantes e visitados, como também em sua memória. Acredita-se que este tipo de experiência possa ser ainda mais genuína com a participação da comunidade na construção, de forma a transmitir a identidade cultural local. De acordo com Silva (2012), a atividade turística começa então, a delinear um novo caminho dentro de um ciclo de mudanças na sociedade globalizada, com bases para a redefinição do comportamento dos visitantes e da função das comunidades locais.

No âmbito do setor, a Eco 92 ${ }^{\text {a }}$, teve sua expressão mais clara quando foi lançada a Carta de Turismo Sustentável. Esta afirma que a atividade deve considerar os efeitos sobre o patrimônio cultural e os elementos, atividades e dinâmicas tradicionais das comunidades locais. " $O$ reconhecimento destes fatores locais e o apoio à sua identidade, cultura e interesses devem ser

\footnotetext{
a Conferência das Nações Unidas sobre o Meio Ambiente e o Desenvolvimento, realizada no Rio de Janeiro, em junho de 1992 . Também conhecida como Cúpula da Terra, ela reuniu mais de 100 chefes de Estado para debater formas de desenvolvimento sustentável, um conceito relativamente novo na época.
} 
referências obrigatórias na formulação de estratégias turísticas, especialmente os países em vias de desenvolvimento." No entendimento desta proposta, isto se relaciona diretamente ao conceito de Design para a valorização dos recursos e competências de um território, abordagem que visa, segundo Krucken (2009), evidenciar os aspectos que conferem identidade ao território, de forma a valorizar a riqueza local - suas atividades, paisagens, patrimônio, conhecimento tradicional, etc.

Uma solução sustentável para problemas de um território, seja ele qual for - uma associação, uma comunidade, um Estado ou um país inteiro, de acordo com Manzini (2008), é o resultado por meio de um produto, processo ou serviço que seja coerente, levando em conta os aspectos ambientais, econômicos, sociais e culturais que o compõem, que devem dialogar diretamente com os atores locais e suas referências. Uma das maneiras de incentivo à produção local, apontada em diversas pesquisas, é pelo investimento no turismo. Esta é uma oportunidade de fazer com que as pessoas conheçam o local de forma mais genuína, principalmente quando este serviço é desenvolvido pelos próprios moradores. Impulsionar o desenvolvimento local através de pequenas ações e mudanças dentro da realidade do território é uma resposta às necessidades atuais.

Lucca (2012) coloca que o design pode assumir uma posição estratégica, como atividade capaz de organizar, gerenciar e antecipar ações, relações e competências para delinear e sistematizar soluções projetuais de natureza coletiva. Além disso, de acordo com Machado (2016), tem a capacidade de incluir diferentes atores no diálogo coletivo para o processo de tomada de decisão, característico de um projeto. Essa posição estratégica envolve uma série de ações que não são pré-definidas, mas pensadas de acordo com o cenário de atuação. No caso da projetação de soluções sustentáveis para territórios, organizações e/ou comunidades, é preciso pensar em maneiras de garantir a qualidade dos contextos de vida, valorizando seu capital territorial.

Nessa perspectiva, é possível então, melhorar a qualidade de vida local, preservando tradições e desenvolvendo novas economias com base em produtos e serviços, além de estabelecer o próprio orgulho como território, buscando evidenciar as especificidades particulares de cada região em relação aos seus aspectos culturais, ambientais e territoriais, dispostos entre os atores e o meio. (PÊGO E MIRANDA, 2014, p.109)

Para isso, o designer passa a atuar como um gestor, na busca por diferenciação, posicionamento de mercado, redução de custos, entre outros, com a capacidade de elaborar uma visão de futuro e o direcionamento estratégico das ações. No setor de turismo, essa visão sistêmica é muito importante, no sentido de contribuir em todas as etapas, desde o diagnóstico local até o plano de ações e avaliação de seus resultados.

O Design de Serviços surgiu ao longo da pesquisa como uma oportunidade para abordar o setor do turismo, com o intuito de orientar o desenvolvimento de forma a entregar experiências de uso satisfatórias. Entendeu-se a proposta de abordagem de Design de Serviços Turísticos como uma maneira de desenhar, planejar, projetar o serviço turístico em determinado território, buscando compreendê-lo com suas potencialidades e limitações e, dentro desta perspectiva, propor soluções que possam ser trabalhadas em conjunto com a comunidade e seus setores.

\section{Design de Serviços Turísticos}

Os serviços podem, assim, ser entendidos como atividades que fornecem benefícios através de ações ou desempenhos entre duas ou mais partes, gerando valor sem, necessariamente, resultar em posse de bens. (SANTOS 2010, p.39) 
O setor de serviços, com esta denominação, surgiu em meados dos anos cinquenta, como oposição às atividades de produção de bens tangíveis e, atualmente, tem grande importância na economia. Na sociedade pós-industrial, grande quantidade do que se consome é serviço, o que tem ocasionado a evolução da lógica de posse para acesso, de proprietário a usuário, numa ação de servir algo ou alguém por meio de um conjunto de experiências, o que pode mudar a perspectiva para uma solução mais sustentável.

O IPEA fala da importância estratégica do setor para o desenvolvimento econômico, destacando que os países que desejam alcançar níveis maiores de desenvolvimento, melhorar as condições de vida de suas populações e a competitividade de suas empresas não podem fazê-lo sem um setor de serviços dinâmico e bem estruturado. Ainda há a questão social: muitos eventos mundiais vêm sendo organizados para discutir sobre a economia dos serviços e como isso pode apoiar e dar suporte a pequenos produtores, comunidades autônomas, dentre outras iniciativas.

Porém, apesar de grande parte das economias já apresentar-se orientada para os serviços e este ser o setor que mais emprega no mundo, responsável por parte considerável do PIB mundial, o setor ainda registra baixos índices de produtividade e inovação (PINHANEZ, 2009; OLIVEIRA, 2016). Se por um lado isto se configura como um ponto negativo, por outro é uma oportunidade de investimento. $\mathrm{O}$ aprimoramento do setor de serviços pode levar a mais contratações, menos gasto com materiais e produtos e, consequentemente, maior qualificação da mão de obra local.

\subsection{Design aplicado aos serviços}

O design de serviços enquanto uma atividade prática da competência do designer ainda é recente. Com o surgimento da economia dos serviços, a integração dos mesmos no discurso do design aconteceu gradativamente, expandindo suas competências ao projetar processos e sistemas que são baseados em experiências (SECOMANDI; SNELDERS 2011), tornando-se uma nova área para a prática, abrangendo, por exemplo, o setor público, de saúde, seguros, bancos, viagens, dentre outros.

Outro caminho de grande importância foi o envolvimento mais de perto com o ser humano, buscando entender a real necessidade das pessoas, estendendo seu campo de conhecimento para as experiências de produtos e serviços, desenvolvendo sistemas com novas fontes de valor, o que trouxe para a sociedade, bem como para o profissional que projeta, o entendimento de que o usuário passa a pagar pela utilização e funcionalidade da solução, usufruindo o serviço muitas vezes de forma totalmente imaterial. Dessa forma, a atividade pode ajudar na inovação dos serviços, pois se aproxima das necessidades dos usuários e os problemas enfrentados pelas organizações, podendo gerar soluções efetivas e desejáveis para quem os utiliza. (HINNIG ET AL, 2015, p.46) Para Suri (2003), como a experiência é pessoal e os usuários podem ter respostas distintas em uma mesma situação, não é possível afirmar que designers possam moldá-la, mas é possível projetar as condições para que ocorram experiências positivas.

Freire (2013) coloca que uma das primeiras definições de design de serviços foi proposta pelo estúdio londrino Live/Work e muitas são as definições e autores que vieram a seguir, discutindo o tema. Lagenbach (2008) coloca que o design de serviços ainda está em processo de conceitualização e sua definição ainda é um pouco "obscura", até pela dificuldade de se definir claramente o termo design (p.30). Neste trabalho optou-se por utilizar a definição apresentada a seguir:

O design de serviços é a aplicação de habilidades e processos já estabelecidos no campo do design aplicado ao desenvolvimento de serviços. Trata-se de um modo criativo e prático de 
Para Stickdorn (2014), o resultado de um processo de design de serviços pode assumir diversas formas: desde estruturas organizacionais relativamente abstratas, processos operacionais, experiências de serviços, até objetos fisicamente concretos (p.16). Pode também atuar como uma ferramenta de planejamento, que considera as diversas dimensões da realidade (CANDI, 2007, p.120) e isso envolve o desenho de sistema de uma organização, sua cultura, valores e normas inerentes, bem como sua estrutura e processos organizacionais (STICKDORN, 2014). Lauren Tan (2009) definiu como sete os principais papeis do designer em projetos de serviços: facilitador, comunicador, construtor de capacidades, estrategista, pesquisador, empreendedor e cocriador. A abordagem do design de serviços se refere então a todo o processo, e não somente ao seu resultado final.

Isto significa uma forma de projetar mais humana, que envolve pensar nas pessoas envolvidas, nos valores locais e na sustentabilidade do território, criando também uma ligação entre as pessoas que oferecem e quem usa o serviço, ao que Cipolla e Manzini chamam de design e serviços relacionais. De acordo com este conceito, a eficácia do serviço é baseada na qualidade das relações que são estabelecidas. O entendimento desta vai além de entregar uma solução, mas de planejar um serviço que considere os dois lados, provocando uma mudança social, adicionando os atores locais no processo e valorizando a cultura e os rituais locais.

\section{Possibilidades e Encaminhamentos}

A partir do estudo desenvolvido neste trabalho, entendeu-se que a aplicação do design de serviços no setor do turismo é viável e desejada, configurando-se como oportunidade para a melhoria da qualidade do serviço, bem como a valorização dos territórios, beneficiando a comunidade local. Isso não quer dizer que o turismo seja a solução imediata para os problemas econômicos, mas que pode ser uma importante atividade complementar à renda dos atores locais, se pensada de maneira a englobar cultura, inovação social e valorização ambiental PARA e COM as comunidades, tendo como pontos chave algumas premissas, como:

$>$ reconhecimento dos recursos locais;

> respeito, preservação e utilização consciente destes elementos;

> aspectos econômicos, culturais, sociais e ambientais;

> participação dos atores locais no planejamento e gestão;

A atuação do design como uma ferramenta para identificar e desenvolver potencial latente nos territórios, tanto humano, como material, ambiental, econômico e cultural demonstra seu potencial combinado ao turismo como uma oportunidade para a atuação em todo o mundo, mas principalmente no Brasil, onde existe uma grande quantidade de recursos materiais e humanos que são, muitas vezes, pouco ou mal explorados, e que poderiam gerar benefícios para as próprias comunidades.

Projetar PARA o território significa promover o reconhecimento e a preservação das identidades e da cultural local. Sua atuação pode ser possível por meio do projeto de serviços ou sistemas de produtos turísticos na ótica da valorização territorial, comportando atividades de natureza organizativa, negociável e gerenciável. Assim, vislumbrou-se um caminho para o turismo como alternativa de valorização e sustentabilidade do território em todos os âmbitos aqui 
mencionados, unindo este conceito ao planejamento, por meio do design. Na imagem a seguir são apresentadas as etapas projetuais possíveis e as competências do design que podem apoiar cada uma delas.

Figura 1 - Possíveis etapas de um projeto de design de serviços turísticos para o território

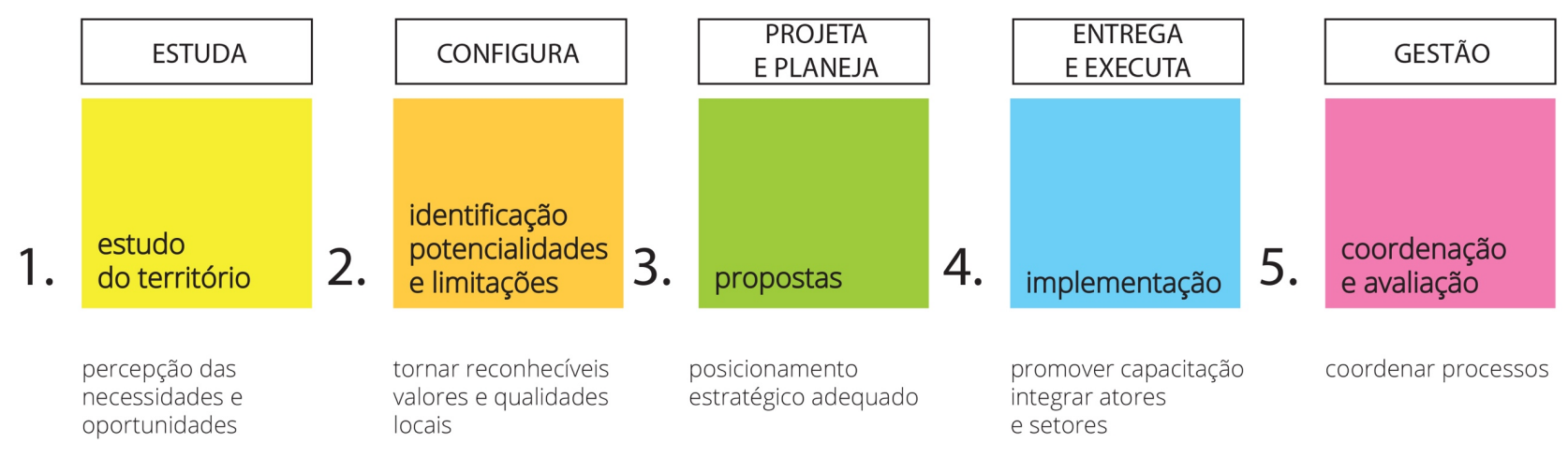

Desenvolvido pela autora

A projetação inicia-se pelo estudo do território e a percepção das reais necessidades daquele local, a partir das atividades que são desenvolvidas ali, das competências locais, bem como suas limitações. A partir da identificação de suas potencialidades e fraquezas, é preciso pensar maneiras de ativar os pontos positivos, trazendo-os à luz, por meio de propostas adequadas àquela realidade. Isso envolve um posicionamento estratégico, onde todas as ações são planejadas. Quando o planejamento está pronto, é hora de implementar os projetos, e muitas vezes são necessárias ações de capacitação, integração, dentre outras possibilidades. A execução das ações possibilita sua avaliação e também sua alteração até que tudo esteja funcionando de uma maneira próxima do ideal. A gestão e coordenação das atividades é contínua e permite revisões constantes, possibilitando seu aprimoramento. Estas etapas são adaptáveis e devem se adequar a cada território, seus atores e sua realidade.

O planejamento e estruturação da atividade turística é um ponto importante, porque envolve pensar os serviços que podem ser oferecidos a partir das competências e limitações locais, ao invés de criar baseado na demanda do público. Também, como já foi mencionado, traz possibilidades de capacitação da mão de obra disponível localmente, possibilitando sua inclusão social e econômica; e de proporcionar a participação ativa da comunidade nos processos de planejamento, decisão e gestão, promovendo a cocriação e a autonomia dos locais.

Entende-se que é possível pensar no projeto do serviço turístico, tentando prever demandas, oportunidades e riscos, por meio do planejamento que ocorre na etapa 3. Esse planejamento possibilita ainda a organização do território, proporcionando desenvolvimento, reafirmação de culturas que, por muitas vezes, podem estar sendo perdidas, além da valorização do patrimônio cultural e natural, isso tudo por meio de decisões coletivas e dialogadas.

O design está, por natureza, vinculado à inovação, o que permite que o mesmo, aplicado ao setor de serviços, se apresente como alternativa para proposição de novos modelos de serviços, ou até mesmo aperfeiçoando os que já existem localmente, como uma alternativa para projetar soluções de serviços de qualidade em territórios diversos. Para isso, é necessário entender bem o contexto do território, sua cultura, a experiência vivida, sua história, deficiências e potenciais. Sua visão sistêmica e estratégica permite identificar potenciais e conectar especialistas que colaborem com problemas específicos, permitindo a cocriação também com os atores locais, formando uma 
rede em que todos podem ser beneficiados.

Como um dos resultados possíveis, a partir do momento em que os visitantes conhecem melhor a cultura local (a historia, a arte, a música, a comida, a religião, a língua, dentre outros), este fator renova o orgulho da população por sua cultura e, ao mesmo tempo, fortalece a identidade local; seus atores passam a criar e difundir novas ideias e novos valores, se apropriando da cultura local, que permanece e se renova. Novos serviços podem ser implantados e melhorar, não somente a experiência do turista como também a vida da população local. Isso compõe um processo em rede, ou efeito dominó positivo, de grande potencial para a valorização dos locais e culturas visitados.

Sobre as possibilidades relacionadas ao design aplicado ao turismo, algumas delas foram pontuadas na imagem a seguir, em forma de esquema gráfico. A partir deste esquema, é possível visualizar que a interligação destes dois setores pode, além de promover a diferenciação de destinos, bem como dos serviços e produtos oferecidos, identificando novas possibilidades, também atuar em prol da comunidade local. Isso significa valorizar tudo que está disponível localmente, o que envolve as pessoas que ali vivem, as atividades que já são desenvolvidas e reconhecidas localmente, as matérias primas típicas daquele local, bem como manifestações culturais, artesanato, gastronomia e outros. Além disso, a proposta de cocriar e pensar soluções junto aos atores locais, cria novos campos de atividades, novas funções e promove a autoestima dessas pessoas, tornando-as parte da solução e criando uma identificação destas com seu território. Dessa forma, as chances de sustentabilidade das ações propostas são maiores, visto que a autonomia dada a aquelas pessoas as torna corresponsáveis pelo sucesso do processo.

Figura 2 - Possibilidades em design e turismo

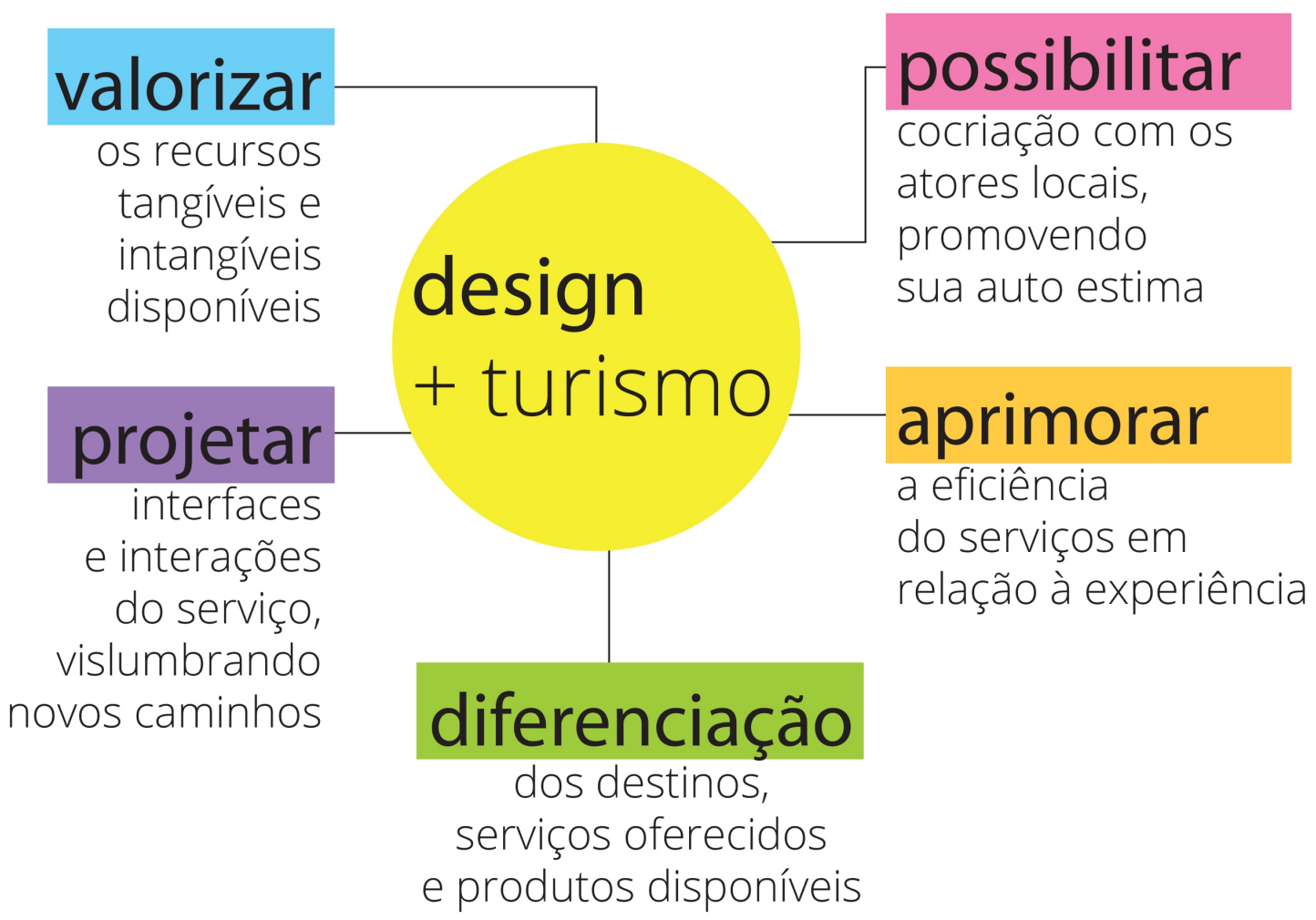

Desenvolvido pela autora 
Este trabalho buscou esclarecer e exemplificar a conexão entre duas atividades de pesquisa e prática: o design e território e o design de serviços, demonstrando o papel do design para coordenação de processos e percepção das necessidades e oportunidades por meio da visão sistêmica, além da otimização de processos e promoção da capacitação dos atores locais, integrando-os em uma rede. Ainda demonstrou a possibilidade de criar novos serviços ou melhorar os já existentes no território e criar diferencial em destinos por meio de soluções sustentáveis para a comunidade.

Sobre o setor do Turismo, foi possível confirmar seu grande potencial para geração de renda e valorização local, mas que nem sempre é aproveitado de maneira correta, ocasionando destruição do ambiente, desvalorização da população local, padronização dos destinos, ocultando seus diferenciais, resultando assim num turismo predatório. Identificou-se que a correta condução da atividade pode proporcionar ao local e às pessoas que ali vivem, uma qualidade de vida maior, o que significa que os benefícios que podem ser gerados vão impactar tanto aos turistas quanto à população local.

Sobre os possíveis benefícios para o território, seu desenvolvimento e o retorno à população local, ilustram-se na imagem a seguir as possibilidades identificadas, distribuindo-as nos aspectos ambientais, culturais, sociais e econômicos.

Figura 3 - Possíveis benefícios ao território

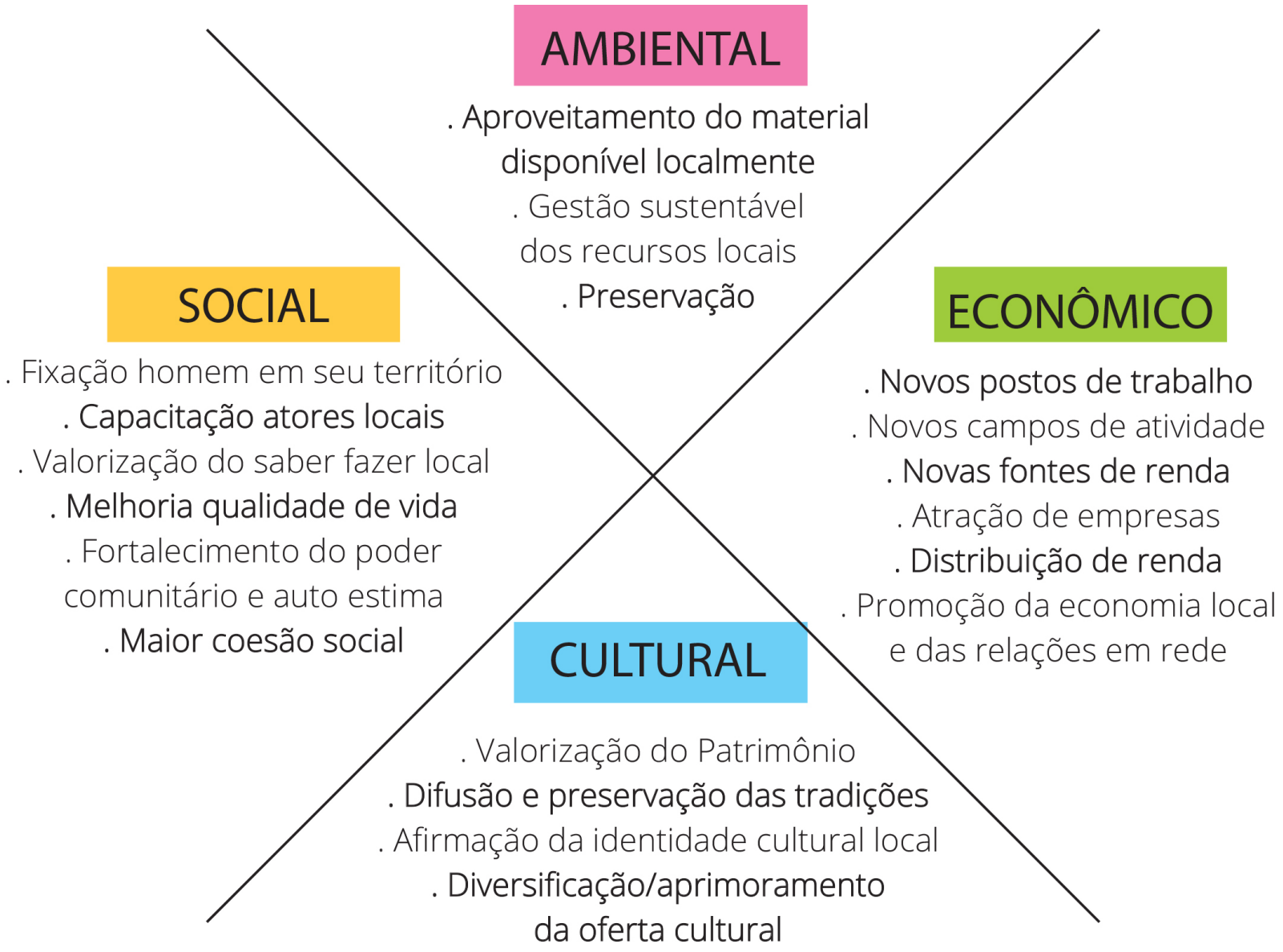

Desenvolvido pela autora.

Este estudo proporcionou novos caminhos e recomendações a futuras pesquisas dentro do Turismo e do Design de Serviços com vistas a valorização do território. Como possíveis 
desdobramentos futuros, estão o aprimoramento deste modelo, e o detalhamento de suas etapas, identificando possíveis ferramentas que possam apoiar esta projetação. A partir daqui, entende-se que muito pode ser feito e desenvolvido. A proposta de trabalhar em pequenos territórios é uma maneira de beneficiar comunidades e/ou arranjos e uma possibilidade de atuação mais eficiente. São muitas as possibilidades existentes em todo o país de aumento da competitividade dos destinos, por meio de capacitação, educação e trabalho, trazendo o retorno local que tanto se almeja.

\section{Referências}

CANDI. The Role of Design in the Development of Technology-based Services. Design studies, 2007 CASTRO, G. V. de. Jardins comunitários de Nova York: um método para recomendações baseado no design de experiência. Tese de Doutorado. Rio de Janeiro: PUC, Departamento de Artes e Design, 2014.

CORIOLANO, L. N. Turismo: prática social de apropriação e de dominação de territórios. In: LEMOS, Amalia Ines; ARROYO, Monica; SILVEIRA, Maria Laura. América Latina, cidade, campo e turismo. Clacso, Consejo Latinoamericano de Ciencias sociales. SP, dez de 2006.

CRUZ, A. R. P. M. Turismo e Criatividade no Algarve: Uma análise da oferta turística regional como elemento de atração da classe criativa. Dissertação de Mestrado. Universidade do Algarve, Faro, 2010.

DIAS, R. Turismo e Patrimônio Cultural - recursos que acompanham o crescimento das cidades. São Paulo, Saraiva, 2006.

FRANZATO, C. Design dei Beni Culturali nel Progetto Territoriale: Strategie, teorie e pratiche de valorizazzione design driven. Milano, 2009. 327p. Tese (Dottorato di Ricerca in Design e tecnologie per la valorizzazione dei beni culturali) - Politecnico di Milano.

FREIRE, K. M. Inovação social dirigida pelo design. In: OLIVEIRA, A. F; FRANZATO, C; DELGAUDIO, C (org). Ecovisões projetuais: pesquisas em design e sustentabilidade no Brasil. São Paulo, Blucher, 2017.

FREIRE, K. M. Design Para Serviços: Uma intervenção em uma Unidade Básica de Saúde do Sistema Único de Saúde Brasileiro. Estudos em Design, Design Articles, 2016.

FREIRE, K. M. Design para serviços: Reflexões sobre o Escopo da Área. In: Menezes, Marizilda dos Santos; Moura, Monica (org). Rumos da pesquisa no design contemporâneo: materialidade, gestão e serviço (ebook). Sao Paulo: Estação das Letras e Cores, 2013.

GARRIDO, I. M. D. A. Modelos multiorganizacionais no turismo: cadeias, clusters e redes. Dissertacao de Mestrado. Salvador, IMDA, 2001.

HINNIG, R; MERINO, G; GONTIJO, L; MERINO, E. Oportunidades de contribuiçãoo do Design de Srrviços para a melhoria da produtividade e inovação. Strategic design Research Journal, no.8, 3748, Unisinos, 2015.

KRUCKEN, L. Design e território: valorização de identidades e produtos locais. São Paulo: Studio Nobel, 2009.

LANGENBACH, M. L. Além do apenas funcional. Inovação social e design de serviços na realidade brasileira. COPPE,UFRJ, Rio de Janeiro, 2008.

LUCCA, A. S. Design Participativo para a Valorização da Produção do Território. In: 10o 
CONGRESSO BRASILEIRO DE PESQUISA E DESENVOLVIMENTO EM DESIGN - P\&D DESIGN, 2012, São Luís. Anais. São Luís: UFMA, 2012.

MANZINI, E. Design para a inovação social e sustentabilidade: comunidades criativas, organziações colaborativas e novas redes projetuais. Rio se Janeiro: E-papers, 2008.

MORITZ, S. Service design: practical access to an evolving field. Kols international school of design, 2009.

OLIVEIRA, L. A. G. Cultura, criatividade e desenvolvimento territorial: reflexões sobre Redes e Sistemas Produtivos de Economia Criativa. In: LEITÃO, Cláudia; MACHADO, Ana Flávia. Por um Brasil criativo: significados, desafios e perspectivas da economia criativa brasileira. Código Editora. Belo Horizonte, 2016.

OLIVEIRA, S. S. Design de serviços: proposição de frameworks para investigação do nível de competência dos designers. Dissertação de mestrado. UEMG, Belo Horizonte, 2016.

PEGO, K; OLIVEIRA, P. Design Sistêmico: Relações entre Território, Cultura e Ambiente no Âmbito da Estrada Real. Strategic Design Research Journal. 7(3) 101-109 setembro - dezembro, 2014.

PINHANEZ, C. "Humans Inside" as the Key Characteristic of Service Systems. In: QUIS 11 - Moving Forward with Service Quality, Wolfsburg, Germany, p. 515-524, 2009.

SANTOS, S. M. Design de Serviços para a sustentabilidade: proposição de um modelo de design para o direcionamento da atividade projetual sustentável - o caso dos serviços turísticos de hospedagem. Recife, UFPE, Dissertação de Mestrado, 2010.

SCHNEIDER, B. Design - uma introdução: o design no contexto social, cultural e econômico. São Paulo: Editora Blucher, 2010.

SECOMANDI, F. Design e as interfaces de serviço. Gramado: Rio Grande do Sul. 11o. P\&D design: Congresso Brasileiro de Pesquisa e Desenvolvimento em Design, 2014.

SECOMANDI, F. Interface matters: postphenomenological perspectives on service design. Tese (doutorado) - Delft: Delft University of technology, 2012.

SILVA, R.E.S; Identidade, territorialidade e turismo comunitário: na lucha pelo reconhecimento. Editorial Académica Española, 2012.

STICKDORN, M. Isto é Design Thinking de Serviços. Porto Alegre, Bookman, 2014.

SURI, F. The experience of evolution: developments in design practice. The design jornal, no.6, 2948, 2003.

WALKER, S. Sustainable by design - Explorations in theory and practice. Earthscan. London, 2006. 